\title{
Uniform and Homogeneous Growth of Copper Nanoparticles on Electrophoretically Deposited Carbon Nanotubes Electrode for Nonenzymatic Glucose Sensor
}

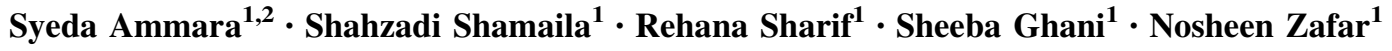

Received: 28 March 2016/Revised: 7 June 2016/Published online: 1 September 2016

(C) The Chinese Society for Metals and Springer-Verlag Berlin Heidelberg 2016

\begin{abstract}
The multiwalled carbon nanotubes thin-film-based electrode was fabricated by electrophoretic deposition and modified with copper $(\mathrm{Cu})$ nanoparticles to fabricate $\mathrm{Cu} / \mathrm{CNTs}$ nanocomposite sensor for nonenzymatic glucose detection. The expensive glassy carbon electrode was replaced by fluorine-doped tin oxide glass containing CNTs film to confine the $\mathrm{Cu}$ nanoparticles growth by electrodeposition through cyclic voltammetry $(\mathrm{CV})$. The ultraviolet visible and X-ray diffraction analysis revealed the successful deposition of $\mathrm{Cu}$ nanoparticles on the CNTs-modified electrode. The atomic force microscopy images confirmed the morphology of electrodeposited $\mathrm{Cu}$ on CNTs film as uniformly dispersed particles. The electrocatalytic activity of electrode to the glucose oxidation was investigated in alkaline medium by $\mathrm{CV}$ and amperometric measurements. The fabricated sensor exhibited a fast response time of less than $5 \mathrm{~s}$ and the sensitivity of $314 \mu \mathrm{A} \mathrm{mM}^{-1} \mathrm{~cm}^{-2}$ with linear concentration range $(0.02-3.0 \mathrm{mM})$ having detection limit $10.0 \mu \mathrm{M}$. Due to simple preparation of sensor, $\mathrm{Cu} / \mathrm{CNTs}$ nanocomposite electrodes are a suitable candidate for reliable determination of glucose with good stability.
\end{abstract}

KEY WORDS: Electrophoretic deposition (EPD); Fluorine-doped tin oxide (FTO) substrate; Carbon nanotubes; Copper nanoparticles; Nonenzymatic electrocatalysis; Glucose sensor

\section{Introduction}

Diabetes mellitus is an extremely extensive disease which transports metabolic disorders and affects about 220 million people around the world. The mortality and morbidity caused by hyperglycemia and insulin deficiency is imitated by higher or lower concentration of blood glucose as compared to the normal range $(4.5-6.5 \mathrm{mM})$

Available online at http://link.springer.com/journal/40195.

Syeda Ammara

ammarashabbir@gmail.com

1 Department of Physics, University of Engineering and Technology, Lahore, Pakistan

2 Department of Physics, Forman Christian College (A Chartered University), Lahore, Pakistan
[1]. Therefore, to establish a simple and rapid glucose sensing system is of significant importance having high stability, sensitivity and selectivity to distinguish different levels of glucose [2-4]. The electrochemical glucose sensors, widely used till today, are enzymatic with high sensitivity and good reliability. However, the catalytic response of the enzyme glucose oxidase (GOx) is sensitive to chemical reagents, $\mathrm{pH}$, temperature and humidity, causing the instability and enzyme damage. Therefore, highly selective nonenzymatic glucose sensors, based on direct glucose oxidation on the surface of electrode without using enzyme, are desired. The nonenzymatic biosensors based on nanostructures [5, 6] have attractive benefits of simple and inexpensive fabrication with good reproducibility and high stability. Most of these nonenzymatic glucose sensors are amperometric.

The nanocomposite-based electrodes with highly active surface area play an important role in the glucose 
electroxidation. Therefore, nanomaterials such as transition metallic nanoparticles and carbon nanotubes (CNTs) have been utilized extensively in biosensors. CNTs are of great importance because of its high chemical stability [7-10] and remarkable physical and electrical properties. Transition metallic nanoparticles (NPs) increase the electrochemical activities due to high surface area, enhanced catalysis and good biocompatibility [10-12]. Hence, it is a significant approach to use them for nonenzymatic glucose sensors, such as Pt NPs- [13, 14], Cu NPs- $[15,16]$, Au NPs- [17, 18], Ni NPs- [19], CNTs-modified electrodes $[20,21]$ and $\mathrm{Cu}$ NPs with CNTs [22, 23]. The fast amperometric glucose detection and high sensitivity have been reported owing to the increase in electroactive surface area. This provides more electron transfer during oxidation reactions of glucose. The electrode materials for glucose analysis based on $\mathrm{Cu}$ nanoparticles are of primary interest for its better catalytic activity, detection limit, range of response and mainly stability [24]. It has been revealed that the catalytic properties can be improved by varying the surface profile, grain size and texture. Therefore, it is a critical requirement to produce nanosized catalysts with improved activities [25]. Continuous efforts have been made to fabricate effectively dispersed $\mathrm{Cu} / \mathrm{CNT}$ composites with increased catalytic activity; however, during recent years, a few reports developed the nonenzymatic glucose sensor with the highly dispersed $\mathrm{Cu} / \mathrm{CNTs}$ nanocomposite electrodes.

In this work, a new, inexpensive and facile route has been employed for the $\mathrm{Cu} / \mathrm{CNT}$ s composite fabrication for the nonenzymatic sensing of glucose and it delivered fairly high sensitivity, good selectivity and reproducibility and fast current response. In fact, the fabrication of pure $\mathrm{Cu}$ nanoparticles is difficult, as they provide poor stability during electroanalysis and easily oxidized in air [12]. The published fabrication methods of $\mathrm{Cu}$ nanoparticles, like microemulsions, reverse micelles and radiation procedures, are complex as all include various solvents [12, 22]. In this project, $\mathrm{Cu}$ nanoclusters were electrodeposited by cyclic voltammetry on CNTs-modified electrode fabricated by electrophoretic deposition. Carboxylic acid ( $\mathrm{COOH}$ )functionalized CNTs were treated with SDS (sodium dodecyl sulfate) to get the most stable suspension for CNTs electrode fabrication through electrophoretic deposition (EPD). The rigid control of deposition rate and film thickness during EPD provides an excellent film uniformity and strong adhesion on electrode surface which is not possible in drop casting and other wet chemical techniques for thin-films fabrication [26-28]. This fabricated $\mathrm{Cu} /$ CNTs composite provides more uniform $\mathrm{Cu}$ deposition on CNTs electrode with better sensing parameters as compared to previously published works with other techniques.

\section{Experimental}

\subsection{Reagents and Materials}

Multiwalled carbon nanotubes (MWCNTs, diameter $\sim 10-20 \mathrm{~nm}$, length $\sim 10-30 \mu \mathrm{m}$, purity $>95 \%$ ) were purchased from Jinzhou Hancheng Import \& Export Co., Ltd. in China and used as received. The chemicals, sodium dodecyl sulfate (SDS), copper sulfate $\left(\mathrm{CuSO}_{4}\right)$, sodium hydroxide $(\mathrm{NaOH})$, potassium ferricyanide $\left(\mathrm{K}_{3}\left[\mathrm{Fe}(\mathrm{CN})_{6}\right]\right)$ and reagents nitric acid $\left(\mathrm{HNO}_{3}\right)$ and sulfuric acid $\left(\mathrm{H}_{2} \mathrm{SO}_{4}\right)$ were purchased from Merck India. Deionized (DI) water was utilized throughout the experiment for aqueous solutions.

\subsection{Preparation of $\mathrm{Cu} / \mathrm{CNTs}$ Nanocomposite Electrode}

The CNTs were $\mathrm{COOH}$ functionalized through refluxing at $60{ }^{\circ} \mathrm{C}$ for $6 \mathrm{~h}$ in $\mathrm{HNO}_{3} / \mathrm{H}_{2} \mathrm{SO}_{4}(1: 3,50 \mathrm{ml})$ mixture. The acid mixture was then re-suspended in DI water and followed by centrifugation at $8500 \mathrm{rpm}$ for $30 \mathrm{~min}$. The centrifugation was performed repeatedly to achieve the neutral $\mathrm{pH}$ solution. The residue was then dried at $25^{\circ} \mathrm{C}$ for $24 \mathrm{~h}$ to yield the $\mathrm{COOH}$-functionalized MWNTs (f-CNTs). To get the effective stable suspension for EPD, f-CNTs were dissolved in aqueous micellar solutions of the anionic surfactant SDS. EPD was conducted using a DC power supply by applying optimized DC voltage (35 V/cm) for 3-min deposition time at room temperature. The working electrode was fluorine-doped tin oxide (FTO) substrate and the graphite used as counter electrode. Both electrodes in the EPD cell were fixed parallel to each other. DC voltage was applied at a constant distance between electrodes. The CNTs-coated FTO substrate was cleaned with DI water to remove any contaminants and dried at room temperature. The obtained electrode was arranged for electrodeposition of $\mathrm{Cu}$. The $\mathrm{Cu}$ electrodeposition was carried out in sulfuric acid solution of copper sulfate $\left(\mathrm{Cu}_{2} \mathrm{SO}_{4}\right)$ by cyclic voltammetry. The scan rate was $100 \mathrm{mV} / \mathrm{s}$ and performed in the potential window of 0.5 to $-0.6 \mathrm{~V}$. The cyclic number was kept 30 to achieve the high reproducibility and sensitivity of the electrodes. The fabricated $\mathrm{Cu} / \mathrm{CNTs}$ composite electrode was stored at room temperature.

\subsection{Characterization Techniques}

The CNTs and $\mathrm{Cu} / \mathrm{CNTs}$ composite electrode was characterized by 2001 Bruker AXS diffractometer using $\mathrm{CuK} \alpha$ radiation. The absorption spectrum of both electrodes was recorded using ultraviolet visible (UV-Vis) spectrophotometer. The surface morphology of the modified electrodes was characterized by atomic force microscopy (AFM). To study the electrochemical properties of the modified electrode, cyclic voltammetry was conducted 
using the Princeton 263 A electrochemical work station having three-electrode configurations with graphite as a counter electrode, a saturated calomel reference electrode and CNTs film electrode as working electrode.

\section{Results and Discussion}

\subsection{Characterization of $\mathrm{Cu} / \mathrm{CNT}$ s Nanocomposite Electrode}

This work provides a simple and inexpensive fabrication approach of $\mathrm{Cu} / \mathrm{CNTs}$ nanocomposite. The use of electrophoretically deposited CNTs electrode has advantages of excellent film uniformity and strong adhesion.

The optical absorbance of electrodeposited $\mathrm{Cu}$ film on electrophoretically deposited CNTs electrode was examined using UV-Vis analysis as shown in Fig. 1. The absorbance peak around 530 and $270 \mathrm{~nm}$ indicates the presence of $\mathrm{Cu}$ nanostructures and optical properties of graphite, respectively [29, 30].

The composite electrode characterized by atomic force microscopy (AFM) is shown in Fig. 2a, b. The Cu deposited on the CNTs electrode exhibits spherical shape with the size from 40 to $90 \mathrm{~nm}$. This large size of $\mathrm{Cu}$ nanoparticles indicates agglomeration of $\mathrm{Cu}$ nanoparticles of much finer size. As the size increases, some adjacent particles coalesce and some particles suffer diffusion interference due to their random distribution resulting in aggregation [31]. The AFM image of electrophoretically deposited CNTs electrode is also shown in Fig. 2c. The image shows a tubular structure with outer diameter of $100 \pm 5 \mathrm{~nm}$ and length range 1000-1200 nm.

The $\mathrm{Cu} / \mathrm{CNTs}$ nanocomposite crystal structure was confirmed by using X-ray diffraction (XRD) determination (Fig. 3). The XRD pattern indicates three peaks at $43.60^{\circ}$, $50.63^{\circ}$ and $74.02^{\circ}$, corresponding to the planes $\{111\}$, $\{200\}$ and $\{220\}$, respectively, which corresponds to the $\mathrm{fcc} \mathrm{Cu}$ lattice. The peak at $32.4^{\circ}$ is assigned to the [002] plane of the CNTs [32]. These results clearly show that the

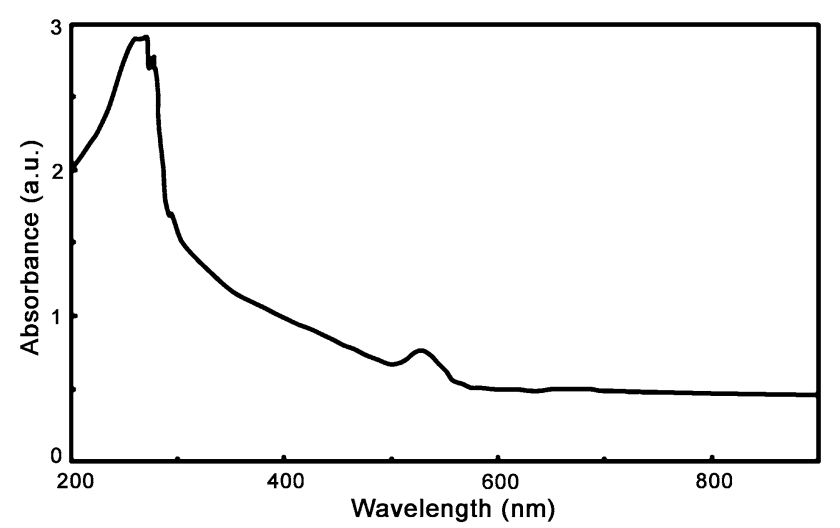

Fig. $1 \mathrm{UV}-\mathrm{V}$ is spectrum of $\mathrm{Cu} / \mathrm{CNT}$ s nanocomposite electrode
$\mathrm{Cu}$ nanoparticles have been successfully electrodeposited on the CNTs-modified electrodes. Based on the experimental results and Scherrer formula, the average crystallite size of $\mathrm{Cu}$ was calculated to be $6.8 \mathrm{~nm}$.

Therefore, the $\mathrm{Cu}$ nanoparticles size of $20-80 \mathrm{~nm}$, perceived from the SEM images, was assembled by the average $\mathrm{Cu}$ nanocrystalline size of $6.8 \mathrm{~nm}$. This indicates that large surface areas of CNTs-modified electrode incorporate the more compact deposition of $\mathrm{Cu}$ nanoparticles [33, 34].

The growth of $\mathrm{Cu}$ nanoparticles on CNTs-modified substrates provides $\mathrm{Cu} / \mathrm{CNT}$ nanocomposites having porous structure, thus providing a perfect interface for utilizing in nonenzymatic electrochemical biosensor.

\subsection{Electrochemical Characterization of $\mathrm{Cu} / \mathrm{CNTs}$ Electrode}

Figure 4 shows the comparison of cyclic voltammograms of CNTs-modified FTO substrate with $\mathrm{Cu} / \mathrm{CNTs}$-modified FTO in $0.5 \mathrm{mM} \mathrm{K}_{3} \mathrm{Fe}(\mathrm{CN})_{6}$ and $0.1 \mathrm{M} \mathrm{KCl}$ at $50 \mathrm{mV} / \mathrm{s}$. The reversible one-electron redox behavior of ferricyanide was observed. The voltammetric behavior of ferricyanide redox couple on the CNTs electrode was found due to the high aspect ratio and surface with electrocatalytic activity. For the $\mathrm{Cu} / \mathrm{CNT}$ n nanocomposite electrode, the cyclic voltammetric response was comparable to that of the CNTs electrode. The voltammograms showed that $\mathrm{Cu}$ was efficiently immobilized on CNTs-coated FTO surface providing the essential conduction paths to promote the transfer of electron at the interface of electrode and analyte like an electrode at nanoscale. With the $\mathrm{Cu}$ nanoparticles deposition on CNTsmodified electrode, peak current $I_{\mathrm{p}}$ has been increased and peak separation $\left(\Delta E_{\mathrm{p}}\right)$ decreased as compared to those of the CNTs-modified electrode. This indicates that the $\mathrm{Cu}$ nanoclusters have increased the electrocatalytic active surface area. Thus, the morphology of the nanostructures played a significant role in revealing the electrochemical activity.

The active surface area was calculated from the RandlesSevcik equation $\left(I_{\mathrm{p}}=2.69 \times 10^{5} n^{3 / 2} A C v^{1 / 2} D^{1 / 2}\right)$, where $I_{\mathrm{p}}$ is the redox peak current $(A), n$ is the electron transfer number $(=1), A$ is the surface area of the electrode $\left(\mathrm{cm}^{2}\right), D$ is the diffusion coefficient $\left(0.76 \times 10^{-5} \mathrm{~cm}^{2} / \mathrm{s}\right), C$ is the concentration of electroactive species $\left(\mathrm{K}_{3} \mathrm{Fe}(\mathrm{CN})_{6}, \mathrm{M} / \mathrm{L}\right)$ and $v$ is the scan rate (V/s). The calculated active surface areas of CNTsmodified FTO and $\mathrm{Cu} / \mathrm{CNTs}$ were 0.75 and $1.32 \mathrm{~cm}^{2}$, respectively. These results clearly showed the increased active surface area of $\mathrm{Cu} / \mathrm{CNTs}$ nanocomposite electrode.

\subsection{Nonenzymatic Electrocatalysis of Glucose at the $\mathrm{Cu} / \mathrm{CNT}$ Electrode}

The electrocatalytic response of the CNTs and $\mathrm{Cu} / \mathrm{CNTs}$ electrode toward glucose oxidation in alkaline media was 

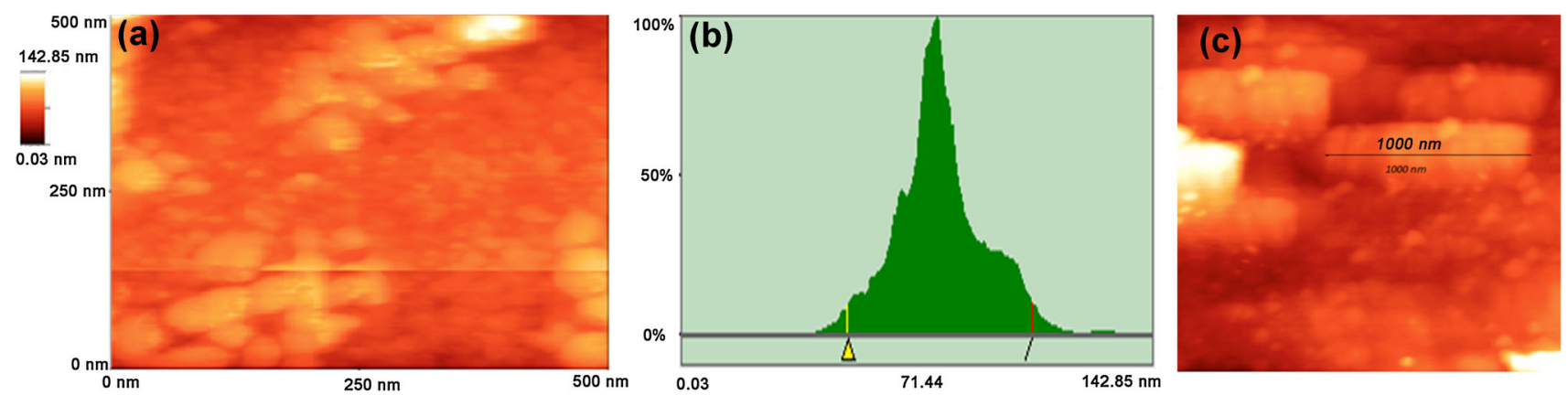

Fig. 2 AFM image a and histogram $\mathbf{b}$ of $\mathrm{Cu} / \mathrm{CNT}$ s nanocomposite electrode; $\mathbf{c}$ AFM image of CNTs-modified electrode

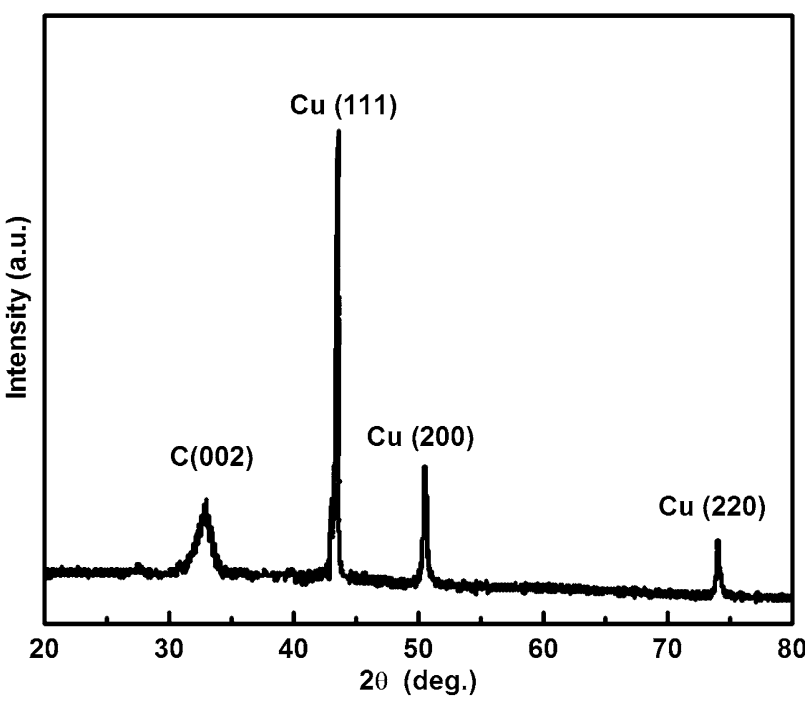

Fig. 3 XRD pattern of $\mathrm{Cu} / \mathrm{CNTs}$ nanocomposite electrode

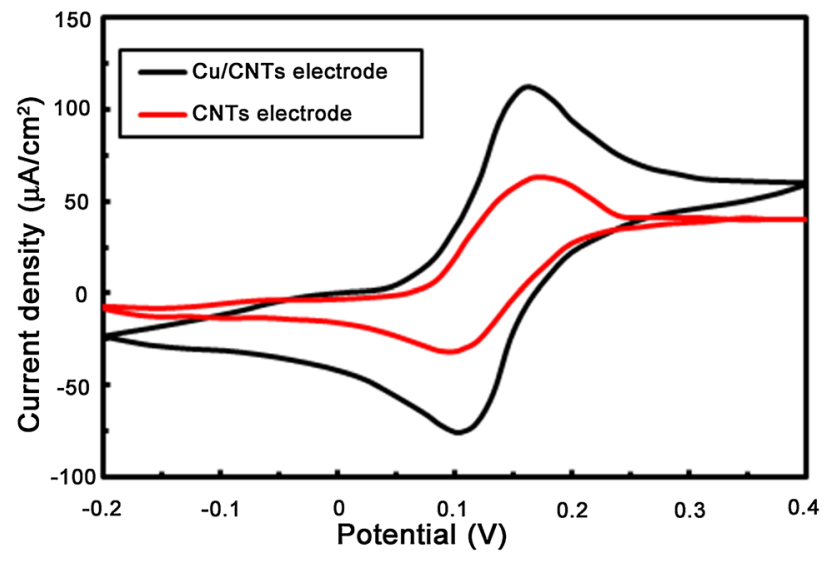

Fig. 4 Cyclic voltammetry curves of CNTs and $\mathrm{Cu} / \mathrm{CNT}$ s electrode at scan rate of $50 \mathrm{mV} / \mathrm{s}$

examined by cyclic voltammetry in $0.1 \mathrm{M} \mathrm{NaOH}$ solution at scan rate of $20 \mathrm{mV} / \mathrm{s}$ in the presence and absence of $0.5 \mathrm{mM}$ glucose as shown in Fig. 5. The potential range was selected from 0.0 to $0.8 \mathrm{~V}$ versus saturated calomel electrode (SCE). The requirement of alkaline medium to improve the effect of $\mathrm{Cu}$ for glucose oxidation is acknowledged. Figure 5 shows that in the glucose absence, no redox peak appears from electrophoretically deposited CNTs electrode and $\mathrm{Cu} / \mathrm{CNT}$ composites electrode. A predominant increase in the reaction peak current was detected upon addition of glucose for $\mathrm{Cu} / \mathrm{CNT}$ s composite as a working electrode. The well-defined pair of redox peak currents at 0.68 and 0.25 is observed from the voltammograms corresponding to the glucose oxidation peaks for $\mathrm{Cu}$ (II)/Cu (III) [8, 23]. Redox peaks from the transition of $\mathrm{Cu}$ (II) and $\mathrm{Cu}$ (III) have been considered as a mediator for electron transfer. These results indicate that $\mathrm{Cu}$ nanoparticles exhibit excellent electrocatalytic response toward glucose oxidation and CNTs electrode provides the large surface area and a high conductivity to increase the electron transfer rate. The detection potential was $0.68 \mathrm{~V}$.

Cyclic voltammetry plot of $\mathrm{Cu} / \mathrm{CNTs}$ nanocomposite electrode in the presence of glucose $(0.1 \mathrm{M} \mathrm{NaOH})$ solution at altered scan rates of $20,60,80,100$ and $150 \mathrm{mV} / \mathrm{s}$ is shown in Fig. 6. The increasing scan rates resulted in shifting the redox peak currents to higher values with more peak-to-peak separation. Figure 6 shows the linear variation of cathodic and anodic peak currents with increasing square root of scan rates demonstrating that the

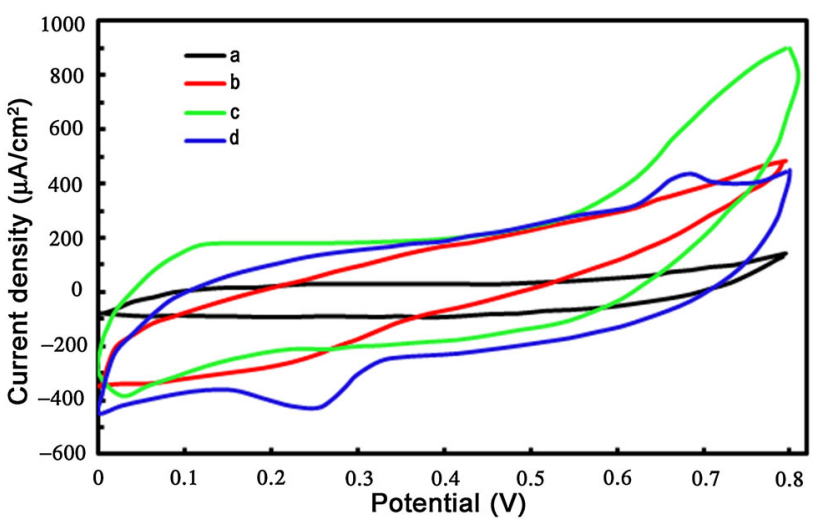

Fig. 5 Cyclic voltammetry of CNTs electrode (curves $a, b)$ and $\mathrm{Cu} /$ CNTs electrode (curves $c, d$ ) before (curves $a, c$ ) and after (curves $b$, $d$ ) adding $0.5 \mathrm{mM}$ glucose in $0.1 \mathrm{mM} \mathrm{NaOH}$ solution at scan rate of $20 \mathrm{mV} / \mathrm{s}$ 
electrochemical reactions are surface controlled by the adsorption of glucose molecule. The correlation coefficients $R^{2}$ of 0.992 and 0.997 for anodic and cathodic peaks, respectively, have been observed.

\subsection{Glucose Detection Response of $\mathrm{Cu} / \mathrm{CNTs}$ Electrode}

Figure 7 demonstrates the amperometric results of $\mathrm{Cu} /$ CNTs composite electrode at optimized potential $(0.65 \mathrm{~V})$. The glucose with varying concentration was successively added in $\mathrm{NaOH}$ solution of optimized concentration $0.1 \mathrm{M}$. Each step of glucose addition generates a rise in current and gets a steady current in less than $5 \mathrm{~s}$. This indicated an extremely rapid and subtle response of $\mathrm{Cu} / \mathrm{CNTs}$ nanocomposite electrode toward glucose along with rapid diffusion of glucose. The electrophoretically deposited CNTs electrode promoted fast transfer of electron providing high electroconductive performance.

The inset in Fig. 7 shows the current density $\left(\mu \mathrm{A} / \mathrm{cm}^{2}\right)$ versus glucose concentration $(\mathrm{mM})$ plot exhibiting linearity. The plot gives correlation coefficient $R^{2}$ of 0.996 and the sensitivity of $\mathrm{Cu} / \mathrm{CNTs}$ nanocomposite sensor $\left(314 \mu \mathrm{A} \mathrm{mM}^{-1} \mathrm{~cm}^{-2}\right)$. The limit of detection was $10.0 \mu \mathrm{M}$. This can be assigned to $\mathrm{Cu}$ nanostructures having high surface area and conductivity.

\subsection{Stability and Reproducibility of the Electrode}

The reproducibility of the nonenzymatic glucose sensor was examined by making five $\mathrm{Cu} / \mathrm{CNT}$ nanocomposite electrodes with same fabrication technique and testing their current responses with $0.5 \mathrm{mM}$ glucose solution in $0.1 \mathrm{M}$ $\mathrm{NaOH}$ solution. After five successive measurements, the reproducible generated current was evaluated having relative standard deviation (RSD) of $4.5 \%$. The RSD of successive 5 electrodes gives RSD of $5.9 \%$. These results show the high reproducibility of $\mathrm{Cu} / \mathrm{CNT}$ s electrode for

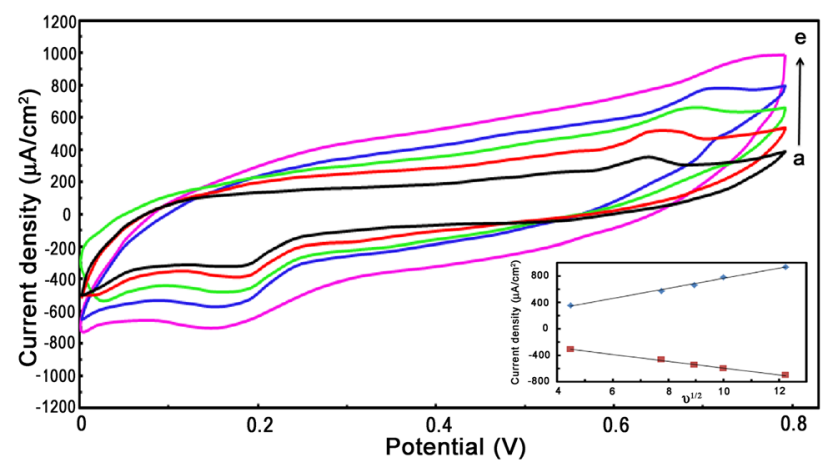

Fig. 6 Cyclic voltammetry curves of $\mathrm{Cu} / \mathrm{CNT}$ s electrode at scan rate of 20,60,80, 100 and $150 \mathrm{mV} / \mathrm{s}$ (curves $a-e$ ). Inset linear variation of redox peak currents with square root of scan rate

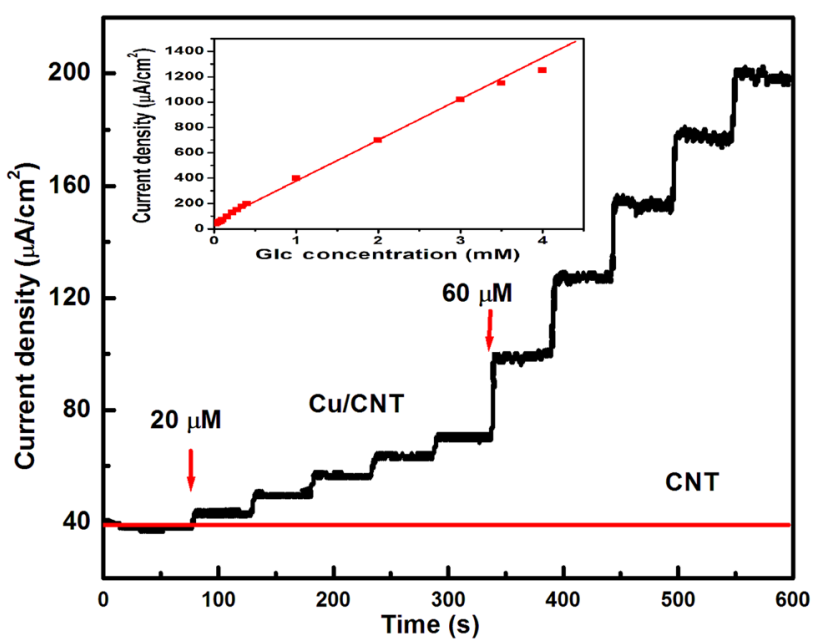

Fig. 7 Current time response of $\mathrm{Cu} / \mathrm{CNT}$ s electrode to various concentration of glucose in $0.1 \mathrm{M} \mathrm{NaOH}$ solution. Inset current response versus glucose concentration

glucose detection. The stability evaluation of electrode was performed by evaluating the current response to $0.5 \mathrm{mM}$ glucose, each with 2-day intervals, as shown in Fig. 8. The $\mathrm{Cu} / \mathrm{CNTs}$ electrode was placed in air, when it was not measured. It was detected that the current response could persist about $90 \%$ of its first value after storing for 20 days, revealing that the electrode offers very good stability.

Some easily oxidized synergetic compounds such as ascorbic acid (AA) and uric acid (UA) give interfering current signals which are the major encounters in the nonenzymatic detection of glucose. Although these intrusive species of AA $(0.002 \mathrm{mM})$ and $\mathrm{UA}(0.002 \mathrm{mM})$ are much lower in concentration than glucose $(3-8 \mathrm{mM})$ in an ordinary biological sample, they generate electrochemical

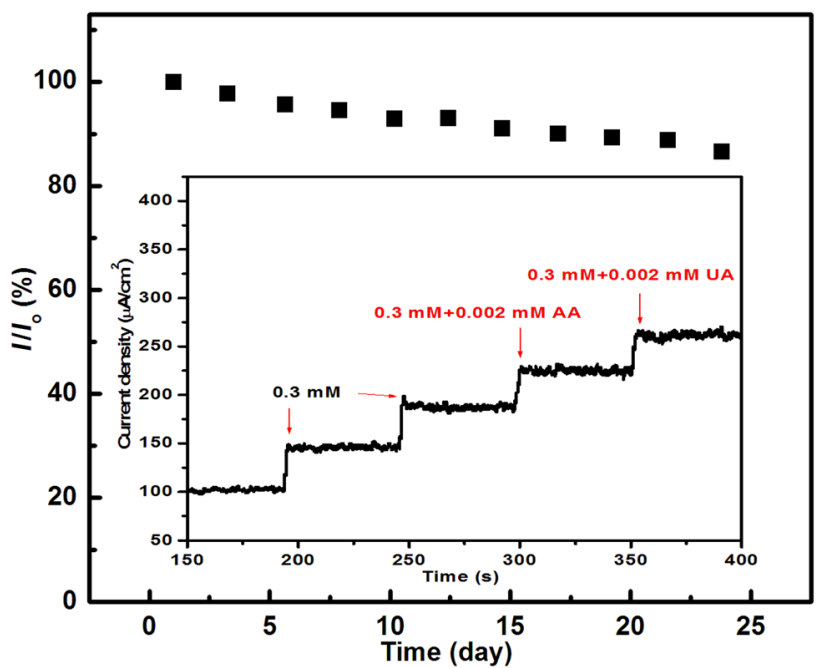

Fig. 8 Stability of the $\mathrm{Cu} / \mathrm{CNT}$ s electrode. The determination solution is $0.1 \mathrm{M} \mathrm{NaOH}$ with $0.5 \mathrm{mM}$ glucose at $0.65 \mathrm{~V}$. Inset interference test of $\mathrm{Cu} / \mathrm{CNTs}$ electrode with $0.3 \mathrm{mM}$ glucose and $0.002 \mathrm{mM}$ each ascorbic acid (AA) and uric acid (UA) 
current values analogous to glucose. This might be due to more transfer of electrons [13]. The inset of Fig. 8 demonstrates the measurements upon addition of $0.002 \mathrm{mM}$ interfering species with continuous addition of $0.3 \mathrm{mM}$ glucose in $0.1 \mathrm{M} \mathrm{NaOH}$ solution. A significant glucose response was detected as compared to UA and AA, thereby neglecting the effect of interfering species. This demonstrates that the fabricated $\mathrm{Cu} / \mathrm{CNT}$ s nanocomposite electrode is precisely specific toward glucose regardless of the intrusive species.

This work provides high sensitivity, fast response, low detection limit and good stability as compared to previously reported works [24, 35-38]. In comparison with other $\mathrm{Cu} /$ CNTs nanocomposite electrodes, the demonstrated advantages of the $\mathrm{Cu}$ deposition on the uniform and homogeneous CNT films showed that these CNT films played highly important role in glucose electrocatalytic oxidation performance. The higher current response of the electrode can be found due to its compact and uniform structure. The improved performance can also be attributed to synergistic electrocatalytic behavior of the CNT films toward glucose oxidation [35]. This work offers a simple and a promising approach to functionalize the CNT thin films for possible application.

\section{Conclusion}

The $\mathrm{Cu}$ nanoparticles have been electrodeposited by cyclic voltammetry on the CNTs film prepared on FTO substrate by electrophoretic deposition, constructing a nonenzymatic amperometric glucose biosensor. The prepared $\mathrm{Cu} / \mathrm{CNTs}$ electrode exhibits fast response of less than $5 \mathrm{~s}$, high stability, good reproducibility and excellent sensitivity $314 \mu \mathrm{A} \mathrm{mM}^{-1} \mathrm{~cm}^{-2}$ with wide linear range (0.02-3.0 mM) and low detection limit $(10 \mu \mathrm{M})$. This value of sensitivity is higher in comparison with previously reported $\mathrm{Cu}$ electrodeposited nonenzymatic glucose sensors, demonstrating the increase in electrocatalytic active surface area by homogenous deposition of $\mathrm{Cu}$ nanoparticles on uniformly coated CNTs substrate. The glassy carbon electrode can be replaced with inexpensive FTO substrate for effective glucose determination with low detection limit, low over potential and high sensitivity. This project offers a promising approach to incorporate the CNTs thin films, prepared by electrophoretic deposition, for potential application. Furthermore, nanocomposites of Ni/CNTs and Ni/Cu/CNTs are in process of fabrication by the same technique for more sensitive nonenzymatic glucose detection.

Acknowledgments This work was supported by the University of Engineering and Technology, Lahore, Pakistan. The authors are highly grateful to the Department of Physics, GCU, Lahore, and Centre of Advanced Studies in Physics (CASP), GCU, Lahore, for providing assistance in XRD and SEM analysis, respectively.

\section{References}

[[1] R. Prehn, M. Cortina-Puig, F.X.M. Pascual, F.J.D. Campo, L. Abad, J. Electrochem. Soc. 159, F134 (2012)

[2] F. Meng, W. Shi, Y. Sun, X. Zhu, G. Wu, C. Ruan, X. Liu, D. Ge, Biosens. Bioelectron. 4, 141 (2013)

[3] B.D. Malhotra, A. Chaubey, S.P. Singh, Anal. Chim. Acta 578, 59 (2006)

[4] J. Wang, Chem. Rev. 108, 814 (2008)

[5] P. Sejin, S.Y. Lee, H. Boo, H.M. Kim, K.B. Kim, H.C. Kim, Y.J. Song, T.D. Chung, Chem. Mater. 19, 3373 (2007)

[6] Y. Sun, H. Buck, T.E. Mallouk, Anal. Chem. 73, 1599 (2001)

[7] H. Zhao, H. Ju, Anal. Biochem. 350, 138 (2006)

[8] A. Merkoc, M. Pumera, X. Lopis, B. Perez, M. del Valle, S. Alegret, Trends Anal. Chem. 24, 9 (2005)

[9] V.G. Gavalasa, S.A. Lawa, J.C. Balla, R. Andrewsb, L.G. Bachasa, Anal. Biochem. 329, 247 (2004)

[10] Y. Lin, X. Cui, X. Ye, Electrochem. Commun. 7, 267 (2005)

[11] M.L. Mena, P. Yanez-Sedeno, J.M. Pingarron, Anal. Biochem. 336, 20 (2005)

[12] C.M. Welch, R.G. Compton, Anal. Bioanal. Chem. 384, 601 (2006)

[13] S. Park, T.D. Chung, H.C. Kim, Anal. Chem. 75, 3046 (2003)

[14] H. Boo, S. Park, B. Ku, Y. Kim, J.H. Park, H.C. Kim, T.D. Chung, Am. Chem. Soc. 126, 4524 (2004)

[15] I.G. Casella, M. Gatta, M.R. Guascito, T.R.I. Cataldi, Anal. Chim. Acta 357, 63 (1997)

[16] Q. Xu, Y. Zhao, J.Z. Xu, J.J. Zhu, Sens. Actuators B Chem. 114, 379 (2006)

[17] M. Tominaga, T. Shimazoe, M. Nagashima, I. Taniguchi, Electrochem. Commun. 7, 189 (2005)

[18] M. Tominaga, T. Shimazoe, M. Nagashima, H. Kusuda, A. Kubo, Y. Kuwahara, I. Taniguchi, Electroanal. Chem. 590, 37 (2006)

[19] T. You, O. Niwa, Z. Chen, K. Hayashi, M. Tomita, S. Hirono, Anal. Chem. 75, 5191 (2003)

[20] J. Ye, Y. Wen, W. Zhang, L. Gan, G. Xu, F. Sheu, Electrochem. Commun. 6, 66 (2004)

[21] R.P. Deo, J. Wang, Electrochem. Commun. 6, 284 (2004)

[22] K.B. Male, S. Hrapovic, Y. Liu, D. Wang, J.H.T. Luong, Chim. Acta 516, 35 (2004)

[23] J. Wang, G. Chen, M. Wang, M.P. Chatrathia, Analyst 129, 512 (2004)

[24] H. Liu, X. Su, X. Tian, Z. Huang, W. Song, J. Zhao, Electroanalysis 18, 2055 (2006)

[25] Y. Xu, X. Lin, Electrochim. Acta 52, 5140 (2007)

[26] L. Besra, M. Liu, Prog. Mater Sci. 52, 1 (2007)

[27] I. Zhitomirsky, L. Gal-or, Mater. Med. 8, 213 (1997)

[28] I. Zhitomirsky, J. Eur. Ceram. Soc. 18, 849 (1998)

[29] S. Pourbeyram, S. Mohammadi, J. Non Cryst. Solids 402, 58 (2014)

[30] Y.L. Yao, X. Bai, K.K. Shiu, Nanomaterials 2, 428 (2012)

[31] L. Cao, P. Diao, T. Zhu, Z. Liu, J. Phys. Chem. B 108, 3535 (2004)

[32] M. Terrones, W.K. Hsu, A. Schilder, H. Terrones, N. Grobert, J.P. Hare, Y.Q. Zhu, M. Schwoerer, K. Prassides, H. Kroto, D.R.M. Walton, Appl. Phys. A 66, 307 (1998)

[33] N. Velinov, D. Dimitrov, K. Koleva, K. Ivanov, I. Mitov, Acta Metall. Sin. (Engl. Lett.) 28, 367 (2015)

[34] H.B. Liu, Z.Y. Huang, B.Z. Guo, Q.Z. Jiao, Z.Y. Xiong, Acta Metall. Sin. (Engl. Lett.) 27, 211 (2014)

[35] X.H. Kang, Z.B. Mai, X.Y. Zou, P.X. Cai, J.Y. Mo, Anal. Biochem. 363, 143 (2007)

[36] X. Qin, Y. Zhao, J.Z. Xu, J.J. Zhu, Sens. Actuators B Chem. 114, 379 (2006)

[37] Y. Wang, W.Z. Wei, J.X. Zeng, X.Y. Liu, X.D. Zeng, Microchim. Acta 160, 253 (2008)

[38] H. Lee, S.W. Yoon, E.J. Kim, J. Park, Nano Lett. 7, 778 (2007) 